\title{
Modulation of the in vivo Covalent Binding of the Carcinogen Benzo(a)pyrene to Rat Liver DNA by Selective Induction of Microsomal and Nuclear Aryl Hydrocarbon Hydroxylase Activity
}

\author{
A. Viviani and W. K. Lutz \\ Institute of Toxicology, Federal Institute of Technology and University of Zurich \\ CH-8603 Schwerzenbach, Switzerland
}

\begin{abstract}
The influence of microsomal (mAHH) and nuclear (nAHH) aryl hydrocarbon hydroxylase activity on the covalent binding of tritiated benzo(a)pyrene to rat liver DNA was evaluated in vivo. Induction of $\mathrm{mAHH}$ was obtained after phenobarbitone treatment ( $180 \%$ of control), which increased DNA binding to $210 \%$, but left the $\mathrm{nAHH}$ unchanged. $\mathrm{mAHH}$ and $\mathrm{nAHH}$ were slightly induced with dieldrin (130\% and 120\%), but the binding remained unchanged. The increasing effect of $\mathrm{mAHH}$ as well as the possibly decreasing effect of $\mathrm{nAHH}$ induction on the binding became obvious when the data of 11 individual rats were used to solve the equation Binding $=a^{\times}(\mathrm{mAHH})+b^{\times}(\mathrm{nAHH})+c$. Multiple linear regression analysis resulted in positive values for $a$ and $c$, a negative value for $b$, and a multiple correlation coefficient $\mathrm{R}=0.82$. An influence of other enzymes involved in the metabolism of benzo(a)pyrene cannot be excluded. The study shows clearly that the binding of a foreign compound to DNA in vivo is not only dependent on microsomal enzyme activities but also on nuclear activities even if the latter are considerably lower than those of microsomes.
\end{abstract}

Key words: Benzo(a)pyrene - DNA-Binding - Carcinogen - Enzyme Induction - Aryl Hydrocarbon Hydroxylase - Rats - Phenobarbitone - Dieldrin.

\section{Introduction}

It is now widely accepted that the covalent binding of a chemical carcinogen to the DNA of the target organ is a critical event in carcinogenesis (Heidelberger, 1975; Lutz et al., 1979). Benzo(a)pyrene (BP), a carcinogenic polycyclic aromatic hydrocarbon, has to be metabolized before it can bind to the DNA (Heidelberger; 1975). This activation to reactive metabolites is catalyzed mainly by the aryl hydrocarbon hydroxylase $(\mathrm{AHH})$, a membrane-bound monooxygenase system (Nebert et al., 
1968). The AHH is found mostly in the liver and is located in the endoplasmic reticulum as well as, with much less activity, in the nuclear membrane (Pezzuto et al., 1978). This enzyme is inducible by different compounds to increased activity (Nebert and Gelboin, 1968; Pezzuto et al., 1978).

In the mechanism of the binding of a reactive metabolite to DNA, one has to take into account that the intracellular diffusion from the site of generation to the target site may be affected by detoxifying mechanisms or reaction with a number of nucleophiles. The nuclear AHH is nearer to the DNA and may, therefore, be very important despite the fact that its activity is very low.

The role of the AHH of the two compartments in the activation of BP to DNAbinding metabolites is elucidated in this report.

\section{Materials and Methods}

Adult male rats (Sprague-Dawley derived, SIV50) weighing 280 to $330 \mathrm{~g}$ at the day of sacrifice were kept and treated with the $\mathrm{AHH}$ inducers as described (Viviani et al., 1978). Twenty hours before sacrifice, $2 \mathrm{ml} / \mathrm{kg}$ of $250 \mu \mathrm{g}$ tritiated BP per $\mathrm{ml}$ corn oil were injected i.p. $\left(500 \mu \mathrm{gBP} / \mathrm{kg} ; 6.3 \times 10^{9} \mathrm{dpm} / \mathrm{kg}\right)$. The animals were killed and the microsomal and nuclear AHH activity was determined as described (Viviani et al., 1978). DNA was isolated according to Markov and Ivanov (1974), and the radioactivity bound to the DNA was measured by liquid scintillation counting.

\section{Results}

Table 1 summarizes the results obtained. Phenobarbitone pretreatment markedly enhanced the mierosomal AHH activity and doubled the amount of BP bound to DNA. Dieldrin did not alter the binding although the microsomal activity was ele-

Table 1. Binding of tritiated benzo(a)pyrene (BP) to rat liver DNA after different induction of microsomal and nuclear aryl hydrocarbon hydroxylase (AHH)

\begin{tabular}{lllc}
\hline Inducer & Microsomal AHH & Nuclear AHH & Binding to DNA \\
\hline None (control) & $2040 \pm 190^{*}$ & $39 \pm 6$ & $6.8 \pm 0.8$ \\
PB 14 days & $3620 \pm 600^{* *}$ & $44 \pm 26$ & $14.2 \pm 8.4$ \\
DI 12 days & $2630 \pm 250^{* *}$ & $48 \pm 15$ & $7.2 \pm 1.9$ \\
\hline
\end{tabular}

Adult male rats were sacrificed after a pretreatment for the time period indicated. $500 \mu \mathrm{g} \mathrm{BP} / \mathrm{kg}$ in corn oil were administered i.p. 20 h before sacrifice. AHH activity is expressed as picomole 3-OH-BP formed in $1 \mathrm{~min} / \mathrm{mg}$ of protein, measured by a fluorimetric assay; binding to DNA as $\mu$ mole $\mathrm{BP}$ bound per mole DNA-phosphate/mmole BP administered per $\mathrm{kg}$ body weight.

Inducer dosages: Phenobarbitone (PB), given continuously in the drinking water at $1 \mathrm{~g} / \mathrm{l}$; dieldrin (DI), $20 \mathrm{mg} / \mathrm{kg}$ i.p. daily in corn oil for the first 3 days; control (CTR), no pretreatment

* Mean \pm S.D.

**Significantly different from control $(p<0.05 ;$ Student's test). 


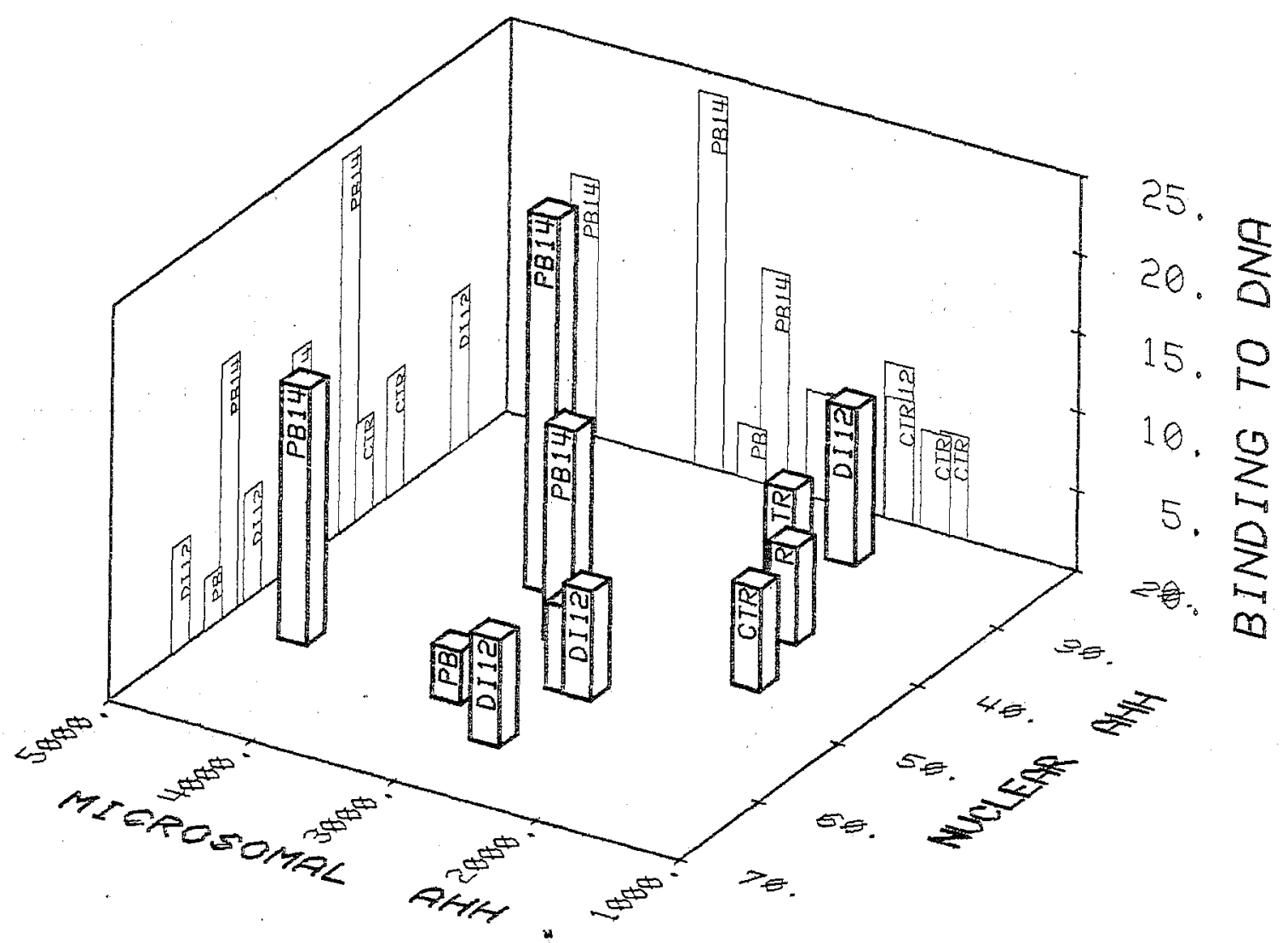

Fig. 1. Binding of benzo(a)pyrene to rat liver DNA as a function of the microsomal and nuclear aryl hydrocarbon hydroxylase activity $(\mathrm{AHH})$. Each bar represents the three values from one individual rat treated as indicated (inducer and days of pretreatment). See legend to Table 1 for further explanations

vated. Neither of the inducers affected the nuclear activity significantly, but there was a tendency to higher activity seen after dieldrin treatment. One might tentatively conclude from these data that the increasing effect of microsomal $\mathrm{AHH}$ induction on the binding is counteracted by increases in nuclear activity.

This hypothesis is corroborated when the data of the 11 individual animals are considered. In.Figure 1, the height of one bar represents the extent of binding of BP to DNA, and its position is dependent on the $\mathrm{AHH}$ activity of the two compartments.

With such a representation, the reducing effect of nuclear $\mathrm{AHH}$ on the binding of BP to DNA comes out much more clearly and the data fit into a linear equation of the form

$$
\text { Binding } \left.=+0.0071^{\times} \text {(microsomal } \mathrm{AHH}\right)-0.36^{\times}(\text {nuclear } \mathrm{AHH})+6.1
$$

with a surprisingly good multiple correlation coefficient $\mathrm{R}=0.82$ and a standard error of the estimation of the binding of 3.8 units.

\section{Discussion}

Our working hypothesis was that the nuclear AHH, which is closer to the DNA, should have an increasing effect on DNA-binding of BP. The data presented show, 
however, that the nuclear activity decreases this binding. It could be concluded that the activation of $\mathrm{BP}$ to reactive metabolites takes place in the endoplasmic reticulum, and that the low activity in the nuclear membrane inactivates these metabolites through further oxidation.

$\mathrm{AHH}$ is not the only enzyme involved in the metabolism of $\mathrm{BP}$. Epoxide hydratase $(\mathrm{EH})$ converts epoxides to dihydrodiols, which are further oxidized to the very reactive diolepoxides (Pezzuto et al., 1978). $\mathrm{EH}$ may also be altered in its activity by the chemicals used in this study. An induction would accelerate the formation of the diolepoxides and increase the binding of $\mathrm{BP}$ to DNA. On the other hand, reactive epoxides are, on their own right, substrates for $\mathrm{EH}$ and are inactivated to hydroxylated compounds. An induction of $\mathrm{EH}$ might therefore lower the binding. To date, there are no data available to decide whether induced $\mathrm{EH}$ would produce a positive or negative change in our in vivo study.

Other enzyme activities which are also inducible are present in microsomes and nuclei. Glutathione transferase, phenol sulphotransferase and glucuronyl transferase are known to inactivate BP metabolites and they may also contribute to alterations in the binding when changed in their activity.

This study shows that the binding of a foreign compound to DNA in vivo is not only dependent on microsomal enzyme activities but also on nuclear activities even if the latter are orders of magnitude lower than those of the endoplasmic reticulum.

\section{References}

Heidelberger, C.: Chemical carcinogenesis. Ann. Rev. Biochem. 44, 79-121 (1975)

Lutz, W. K., Schlatter, C.: In vivo covalent binding of chemicals to DNA as a short-term test for carcinogenicity. In: Mechanism of toxic action on some target organs. Arch. Toxicol., Suppl. 2, pp. 411-415. Berlin-Heidelberg-New York: Springer 1979

Markov, G. G., Ivanov, I. G.: Hydroxyapatite column chromatography in procedures for isolation of purified DNA. Anal. Biochem. 59, 555-563 (1974)

Nebert, D. W., Gelboin, H. V.: Substrate-inducible microsomal aryl hydroxylase in mammalian tissue culture I. Assay and properties of induced enzyme. J. Biol. Chem. 243, 6242-6249 (1968)

Pezzuto, J. M., Yang, C. S., Yang, S. K., McCourt, D. W., Gelboin, H. V.: Metabolism of benzo(a)pyrene and (-)-trans-7,8-dihydroxy-7,8-dihydrobenzo(a)pyrene by rat liver nuclei and microsomes. Cancer Res. 38, 1241-1245 (1978)

Viviani, A., Lutz, W. K., Schlatter, C.: Time course of induction of aryl hydrocarbon hydroxylase in rat liver nuclei and microsomes by phenobarbital, 3-methylcholanthrene, 2,3,7,8-tetrachlorodibenzo-p-dioxin, dieldrin and other inducers. Biochem. Pharmacol. 27, 2103-2108 (1978) 